\title{
DECISIONS AND COORDINATION OF RETAILER-LED FRESH PRODUCE SUPPLY CHAIN UNDER TWO-PERIOD DYNAMIC PRICING AND PORTFOLIO CONTRACTS
}

\author{
BO YAN*(i) AND LigUO HAN
}

\begin{abstract}
Fresh agricultural produce is almost the staple food and necessity of people's daily diet all over the world. However, natural perishability and freshness affect the demand for fresh agricultural produce. Due to the change of freshness, the retailer has to adopt a multi-period dynamic pricing strategy to deal with unsold products. The research object of this paper is the retailer's two-echelon supply chain of fresh agricultural produce, and the aim is to achieve the optimal two-period coordination and ordering through options and wholesale contracts in the supply chain. In the case of two-period pricing, we find that the optimal wholesale order quantity increases with the decline of the price in the first period and tends to be stable with the decline of the price in the second period. In contrast, the price change in the first period has a greater impact on the retailer's optimal order quantity. The profits of both the retailer and the supplier increase significantly with the increase of the price in the first period, while the impact of the change of the price in the second period is not obvious. Meanwhile, decentralized decision-making can only be coordinated in the supply chain through the original option contract at the first-period price. In the second period, the cost-sharing contract is introduced to coordinate the supply chain, increase orders, and increase the profits of both the retailer and the supplier. These findings are of great significance for both the retailer and the supplier in the multi-period dynamic pricing of fresh produce under the option contract.
\end{abstract}

Mathematics Subject Classification. 68U20, 90B05.

Received January 25, 2021. Accepted January 3, 2022.

\section{INTRODUCTION}

There is a great demand for fresh vegetables and fruits in the Chinese market. Fresh agricultural products are the staple food in Chinese diet, which leads to a large market scale of fresh agricultural produce and low elasticity of consumer demand. According to the food consumption standard of the State Council of PRC in 2020, the total consumption of fresh agricultural products is estimated to be around 420 million tons, while the annual production of fresh agricultural products in China has exceeded 1.1 billion tons in 2018, which implies that the market has entered a phase of structural oversupply and that it has turned to the buyer's market. Therefore, all agricultural supply chains must be repositioned around the end customer. With the orientation of service economy to customers, the structure of supply chain has changed. Retailers such as

Keywords. Fresh agricultural product supply chain, portfolio contract, two-period dynamic pricing, supply chain coordination.

School of Economics and Finance, South China University of Technology, Guangzhou 510006, P.R. China.

${ }^{*}$ Corresponding author: yanbo@scut.edu.cn 
Walmart, Yonghui Supermarket, Freshippo, and Missfresh, together with other large supermarkets or fresh food e-commerce platforms, are increasingly dominating the fresh agricultural produce market. More and more supply chains are dominated by the retailer rather than the supplier, which significantly affects the decision-making of supply chain management.

The natural perishability of fresh agricultural products causes the consumer demand to be influenced by freshness and selling price [7]. Retailers usually use the dynamic pricing strategy to sell produce. Agricultural products with low freshness will be unsalable if they keep the original price. Customers will choose fresher products or alternative products from other retailers at the same price. In order to achieve greater profits, retailers must sell products with lower freshness at a lower price within a limited time. Therefore, retailers adopt different dynamic pricing strategies in different periods and stages according to the freshness of agricultural products. These pricing strategies influence customers' purchase decisions, thus affecting the market demand and profits of enterprises in different periods. This paper studies the situation that retailers sell fresh agricultural products at two-period pricing in order to reduce unsalable products and stimulate market demand when the freshness of agricultural products decreases.

As mentioned above, the uncertainty of demand leads to shortages and overages, which brings problems for retailers. Meanwhile, fluctuating demand forces suppliers to pay extra to maintain the flexibility of their production capacity. Option contract originated from financial derivatives. As a flexible strategy for suppliers and retailers to reduce risk, it is becoming more and more popular in the supply chain management of fresh agricultural products. Option contracts provide retailers with order flexibility without burdening suppliers. In fact, option contracts are attractive to suppliers because they can receive advance payments. However, option contracts also distribute the risk posed by uncertain demand between retailers and suppliers $[6,17]$. There are several option contract types, such as call option, bidirectional option, and put option. The call option allows retailers to pay a reservation fee for certain goods at the option price before demand is determined. When the selling season commences, the initial market demand is revealed. Once the information about the actual market demand is collected, the retailer can choose to purchase the reserved quantity or purchase order, usually a smaller choice, by paying an additional exercise price. Thus, option contracts help retailers flexibly determine the supply and price when facing the uncertainty of future demand. Once more data about actual demand are collected, they can flexibly determine the order quantity. The most important decision-making issues in option contracts for supply chain management are ordering, option pricing, retail pricing, and coordination [11,12,24].

Considering the joint effect of freshness and price on demand, this paper integrates risk management into option contracts from financial derivatives for the fresh produce supply chain. Using game theory, a new perspective on decision-making is drawn for the circulation of fresh agricultural products, including the optimal ordering and supply chain coordination of two-period option contract and wholesale pricing. Some meaningful conclusions are drawn, and the corresponding insights of supply chain management are put forward.

Section 2 reviews related literature. Section 3 lists the problem descriptions and assumptions. Section 4 discusses the optimal ordering in the retailer's decision-making. Section 5 focuses on the optimal production in the supplier's decision-making. Section 6 discusses the coordination of the fresh agricultural produce supply chain. A numerical analysis is performed in Section 7 to provide further insights. The conclusions and recommendations for further research are discussed in Section 8.

\section{LiteratURE REVIEW}

The literature reviewed in this study is discussed from three perspectives: (1) the retailer-led supply chain; (2) option contracts in risk management; (3) the two-period dynamic pricing for fresh agricultural products.

Participants in the supply chain usually hold different levels of negotiation ability, so the decision-making process must take into account the power structure, which affects the profitability of the participants [19,22]. This study focuses on the scenario in which the supply chain is led by a dominant retailer. The relationships between the different members of the supply chain are most suitably investigated through game theory $[23,35]$, 
and different games can correspond to the different levels of power that are intrinsic to supply chain members. In the case of a dominant retailer with more information, bargaining power, and influence than the supplier, the retailer plays a Stackelberg game as the leader $[36,43]$. In the past, there is no lack of research on the retailerled game model. Li et al. [14] put forward revenue-sharing contracts to coordinate the retailer-led supply chain and explore the impact of coordination mechanisms after demand disruptions. Raju and Zhang [31] proved that the two-part tariff scheme and quantity discount are not effective mechanisms to coordinate the retailerled supply chain when fixed advertising service costs are considered. Taleizadeh and Noori-Daryan [33] used Stackelberg game theory to study policies for manufacturing, pricing optimization, and inventory management to coordinate suppliers, manufacturers, and retailers a supply chain with three levels. In their model, retailers and manufacturers lead the supply chain in the first two phases, when the demand depends on price and out-of-stock status is not allowed. Taleizadeh et al. $[35,36]$ also conducted relevant studies. From the above literature, we recognize that retailer-led supply chains can be studied from multiple perspectives. However, the aforementioned studies mainly focus on the single-period situation. There are few documents on multi-period (e.g., two-period) management of retailer-led fresh agricultural product supply chains.

Many scholars and practitioners recognize the value of option contract in the supply chain risk management. Feng and $\mathrm{Wu}[10]$ and $\mathrm{Xu}$ and Chan [42] analyzed the risks of both the supplier and the retailer under the option contract. By studying risk transfer, Jörnsten et al. [13] found that the status of retailers will always be improved in the option contract setting with discrete demand. Chen et al. [4] explored different decisions such as supply chain coordination with option contracts, ideal production of risk-neutral suppliers, and ordering of loss-averse retailers. Wang et al. [40] examined the scenario in which two risk-averse retailers compete through promotion in order to derive the conditions of channel coordination under option contracts. According to Luo et al. [18], the option contract can help both the manufacturer and the supplier deal with risks effectively, and the researchers proposed an additional option contract agreement to improve supply chain coordination. Li et al. [15] proposed a game model for the commitment option contract in the production and ordering with decentralized decisionmaking by manufacturers and retailers in a supply chain. Zhao et al. $[45,46]$ found that the call option can benefit both risk-neutral suppliers and risk-averse retailers. Their research examined how the profits of supply chain members are affected by uncertain demand, stochastic yield volatility, option contract parameters, and instantaneous purchase price volatility. Zhuo et al. [48] considered risks in the option contract for the twoechelon supply chain to examine the channel coordination with risk constraints. To determine optimal ordering and pricing in the supply chain in which retailers must deal with demand uncertainty and customer returns, suppliers provide both option contracts and wholesale pricing. Wang et al. [41] developed a newsvendor model for their investigation. According to Yuan et al. [44], the order quantity of risk-averse retailers decreases with the decline of exercise price and option price, and will be equal to or lower than that of risk-neutral retailers based on the emergency purchase price. Their study also aimed to obtain the optimal option pricing for a risk-neutral Stackelberg game led by the supplier. An algorithm proposed by Eriksson [9] combines the option contract with the basic inventory model to solve the important problem of ordering and production decisions in multiple periods in dual supply chains bilaterally.

In recent years, the research on option contract of fresh agricultural products circulation management has gradually increased. Due to the perishability of fresh agricultural products, there are great risks in demand uncertainty and losses in the circulation process. Wang and Chen [38] proposed a Stackelberg model for the agricultural produce supply chain consisting of one supplier and one retailer. They proposed a call option contract with linearly dependent option price and exercise price, and derived the ideal option pricing for the supplier, but demonstrated that the fresh agricultural produce supply chain cannot be coordinated. Furthermore, Wang and Chen [39] analyzed pricing and joint order decision-making in combination with put options of fresh agricultural products. An analysis of two-period ordering under different option contracts and the related coordination problems was conducted by Wan et al. [37]. Zhou et al. [47] proposed a channel and information sharing coordination mechanism for the demand uncertainty in the fresh agricultural produce supply chain. In summary, although the option contract in supply chain management has attracted more and more attention, 
there are few studies on its application in the fresh agricultural products industry. In addition, few researchers have focused on the coordination of wholesale and option contract pricing in the circulation of fresh agricultural products.

In general, perishable products, especially fresh agricultural products, may lose some or all of their original functions and values over time. Dynamic pricing strategies are invaluable for retailers whose products must be sold out before a certain deadline in order to maximize profits. There is abundant literature on dynamic pricing strategies for perishable products. Dynamic pricing implements pre-announcement pricing and response pricing in multiple periods with or without consideration of inventory [16]. Cachon and Swinney [2] considered how retailers make decisions on purchase and pricing under responsive pricing when strategic consumers appear in a limited selling season. Dasu and Tong [8] analyzed schemes of pre-announcement pricing and dynamic pricing in a multi-period environment with fixed quantity. Bhattacharjee and Ramesh [1] proposed a multi-period model of profit maximization for the management of retail supply chains of perishable and non-perishable goods. For situations with demand uncertainty and price decline, Pan et al. [26] suggested a model for two periods of ordering and pricing for leading retailers. Sato and Sawaki [32] considered the continuous-time dynamic pricing problem when competitors adopt static pricing policies. Chen et al. [5] explored decision-making and pricing when the customer is loss averse and the demand is influenced by selling price as well as memory-based reference price. When demand is dependent on price, Maiti and Giri [21] considered the policy of two-period pricing in the two-echelon supply chain. Liu et al. [16] looked into the problems of market demand uncertainty and product review uncertainty, and their impacts on two-period pricing strategies for supply chains with uncertain retailers and suppliers. The aforementioned literature provides an in-depth and fruitful view on multi-period dynamic pricing and decision-making in fresh agricultural produce supply chain, but few scholars consider the twoperiod pricing for retailers of fresh agricultural products. Most retailers currently take a dynamic approach to the pricing of fresh agricultural produce because of the complexity of fresh produce pricing. Hence, this study mainly focuses on two-period pricing.

In summary, there is abundant research on the problems caused by the perishability of goods in the fresh agricultural produce supply chain. This study uses game theory to examine the decision-making and coordination of two-period pricing in the fresh agricultural produce supply chain that utilizes option contract, wholesale pricing, optimal ordering, and two-period pricing.

\section{PROBlem DESCRIPTION AND ASSUMPTIONS}

This study considers a two-echelon fresh agricultural produce supply chain with a farmer cooperative as supplier and a supermarket as retailer. The farmer cooperative is an organization which helps farmers concentrate their products to overcome the difficulties such as separate sales and negotiation. Farmer cooperatives also protect the rights and interests of farmers. At present, rural farmer cooperatives are widespread in China [29]. Facing stochastic demand, the supermarket, as the retailer, is more powerful in a retailer-led supply chain, and sells fresh agricultural products to terminal customers after ordering these products from the farmer cooperative. Fresh agricultural products are perishable over time. Because freshness and price influence consumer demand [7], it is necessary for the supermarket to sell products with lower freshness at lower prices to stimulate consumer demand and prevent products from becoming unsalable. Meanwhile, because fresh agricultural products have long lead times and short selling seasons, supermarkets are unable to quickly replenish inventory at the beginning of the selling season. Therefore, important decisions have to be made before the selling season begins for both the farm cooperative and the supermarket. The parameters and variables of this study are shown in Table 1. "Supplier" and "retailer" refer to the "farmer cooperatives" and "supermarket" respectively.

Here, we divide the selling season into two commonly recognized first and second periods. The freshness of fresh agricultural products decreases with time. Hence, in the first-period, the fresh agricultural products will be sold at a normal price $p_{1}$, and in the second period, they will be sold at a lower price $p_{2}$, obviously, $p_{1}>p_{2}$. The retailer provides the option contract and the wholesale price contract to the supplier before the beginning 
TABLE 1. Notations.

\begin{tabular}{ll}
\hline \hline Notation & Description \\
\hline$p_{1}$ & Retailer's first-period unit selling price \\
$p_{2}$ & Retailer's second-period unit selling price \\
$c$ & Supplier's unit production cost \\
$w$ & Supplier's common wholesale price for both periods \\
$w_{1}$ & Unit price of option \\
$w_{2}$ & Unit exercise price of option \\
$g$ & Supplier's unit shortage cost \\
$h$ & Retailer's unit shortage cost \\
$Q_{s}$ & Supplier's production volume \\
$Q_{r}$ & Quantity of fixed wholesale ordered by the retailer in both periods \\
$q_{0}$ & Quantity of ordered options \\
$q$ & Quantity of exercised options \\
$\lambda_{1}$ & First-period product freshness at a given $t$ \\
$\lambda_{2}$ & Second-period product freshness at a given $t$ \\
$D$ & Demand for both selling periods, $i . e . D=d_{1}+d_{2}$ \\
$d_{1}$ & First-period demand \\
$d_{2}$ & Second-period demand \\
$\alpha$ & Market capacity \\
$\beta_{1}$ & First-period elasticity between price and demand \\
$\beta_{2}$ & Second-period elasticity between price and demand \\
$\gamma$ & Elasticity between demand in one period and price in another period \\
$t$ & Circulation time of fresh produce from supplier to consumer \\
$T$ & Life cycle of fresh produce \\
$\varepsilon$ & Continuously distributed random factor with a mean of 1 \\
$f(x)$ & Probability density function of random factor $\varepsilon$ \\
$F(x)$ & Probability distribution function of random factor $\varepsilon$ \\
$\Pi_{s}$ & Supplier's expected profit \\
$\Pi_{r}$ & Retailer's expected profit \\
$\Pi$ & Total expected profit of the supply chain \\
\hline & \\
& \\
\hline &
\end{tabular}

of the selling season. The same unit wholesale price $w$ is set for the two selling periods in the wholesale price contract. Firm order refers to the way that the retailer purchases fresh agricultural products by opting for the wholesale price contract. The option contract includes the following parameters: the unit price of option $w_{1}$ and the unit exercise price of option $w_{2}$. The quantity of exercised options $q$ will not exceed the quantity of option orders of the retailer $q_{0}$. The retailer bears all risks under the wholesale price contract when faced with price volatility, unreliable supply, and unsold products. Option contracts. On the other hand, the option contract mitigates these risks by providing the retailer with supply reliability, flexibility and price. In a supply chain led by the retailer, the supplier tends to accept the option contract if the option contract allows the supplier to obtain a reasonable profit.

Figure 1 shows the decision-making process of the Stackelberg game model divided into two stages. Firstly, during the lead-time to the start of the selling season (from $t_{0}$ to $t_{1}$ ), an initial demand is forecasted, and the retailer provides a combination $\left(w, w_{1}, w_{2}\right)$ of both a wholesale price contract and an option contract. The retailer also indicates the quantity of firm orders to purchase under the wholesale price contract $\left(Q_{r}\right)$ and the quantity of options to order under the option contract $\left(q_{1}\right)$. If both contracts allow the supplier to make considerable profits, the supplier accepts the contract terms and decides the production $\left(Q_{s}\right)$ at the unit production cost $c$ to meet the retailer's total quantity of orders, obviously, $Q_{s}=Q_{r}+q_{0}$. Secondly, when the selling season commences $t_{1}$ (selling season: from $t_{1}$ to $t_{2}$ ), the retailer obtains the firm orders for fresh agricultural products 


\section{Retailer:}

-set wholesale price $w$ and order quantity $Q_{r}$ -set option price $w_{1}$, option exercise price $w_{2}$ and purchase options $q_{0}$

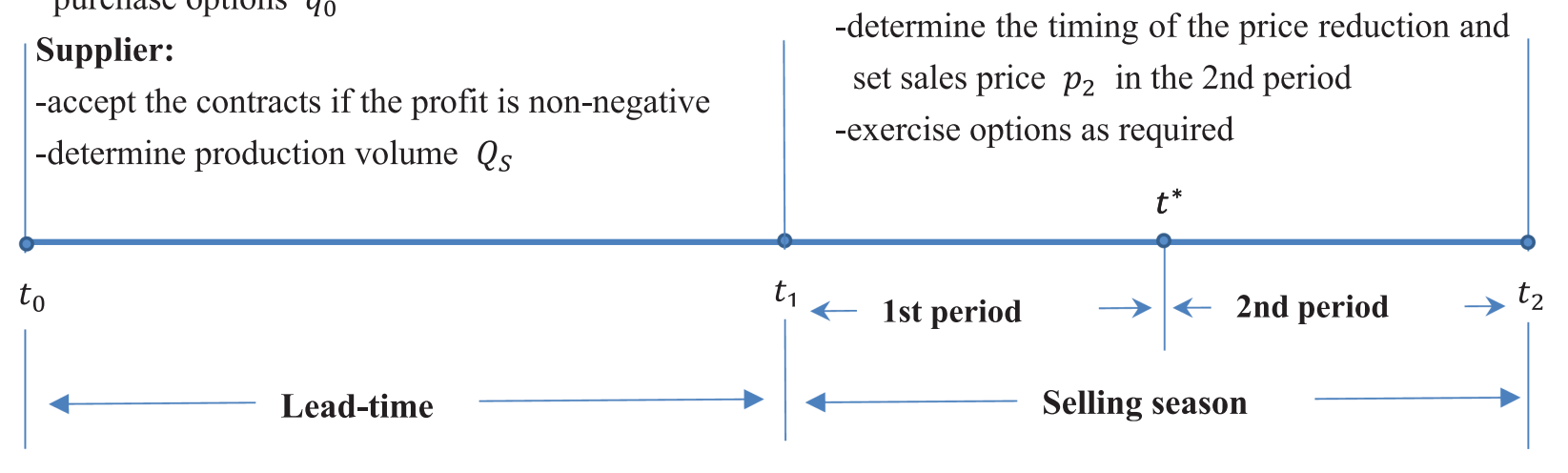

\section{Retailer:}

-set sales price $p_{1}$ in the 1 st period -determine the timing of the price reduction and set sales price $p_{2}$ in the 2 nd period -exercise options as required

FiguRE 1. The decision-making process and parameters.

and decides two selling prices $p_{1}$ and $p_{2}$ in the first and second period, respectively, because the freshness of the products decreases over time. Additionally, during the selling season, the quantity of option exercised by the retailer is determined by $q$ once the actual demand is known. There is also a penalty cost $h$ for any unmet demand. We also assume that the supplier will not be in default and will meet the retailer's order quantity on a contractual basis. Due to the perishability, any unsold agricultural products remaining after the sales season have no residual value.

We adopt the factor of freshness $\lambda(t)=1-\frac{t^{2}}{T^{2}},(\lambda \in[0,1], 0 \leq t \leq T)[20,27,30]$ to describe the level of freshness of the agricultural products, where $t$ refers to the complete circulation time of the goods from the supplier to consumers, while $T$ represents the life cycle of the goods. The freshness of fresh agricultural products decreases with time, i.e., $\frac{\partial \lambda}{\partial t} \leq 0, \frac{\partial^{2} \lambda}{\partial t^{2}}<0$, where $\lambda(t)=1$ or 0 indicates the complete freshness or complete decay (or deterioration) of the agricultural products, respectively.

The retailer dominates the market and can implement demand management by adjusting prices. Meanwhile, it is well known that consumers are very sensitive to the freshness and selling price of fresh agricultural products, which jointly affect the market demand. The demand in both periods is $d_{1}=\left(\alpha-\beta_{1} p_{1}\right) \lambda_{1} \cdot \varepsilon$ and $d_{2}=$ $\left(\alpha-\beta_{2} p_{2}+\gamma p_{1}\right) \lambda_{2} \cdot \varepsilon$, where $\alpha$ indicates the market capacity, $\beta_{1}$ and $\beta_{2}$ describes the elastic relationship between demand and price in the two periods, and $\gamma(\gamma \in(0,1))$ represents the elastic relationship between price and demand in another period $[5,21,25,28]$. The random factor $\varepsilon$ is defined as a continuous distribution with a mean of 1 , and $f(x)$ is the probability density function of $\varepsilon$. The cumulative distribution function $F(x)$ is a continuous strictly increasing function, while the inverse function is defined as $F^{-1}(x)$, and $F(+\infty)=1$, $F(x)=0$.

The parameters satisfy $p_{1}>p_{2}, 0<w<w_{1}+w_{2}, 0<w_{1}+w_{2}<p_{1}+h, 0<c<w<p_{1}$, where $h$ represents the retailer's unit shortage cost. The supplier's shortage cost $g$ is greater than the production cost $c$, so $g-c>0$.

We further assume that both members of the supply chain are rational and self-interest, and each member can maximize its expected profit.

\section{RETAILER'S OPTIMAL ORDERING DECISION-MAKING}

It is assumed that the supplier can adequately meet the retailer's order quantity according to the contract, i.e., there is no default, and $Q_{S} \geq d_{1}+d_{2}$. Therefore, no matter how the sales price changes, the retailer's option is exercised as follows. 
It is assumed that the supplier can adequately meet the retailer's order quantity according to the contract, i.e., there is no default, and $Q_{S} \geq d_{1}+d_{2}$. Therefore, no matter how the sales price changes, the retailer's option is exercised as follows.

$$
q= \begin{cases}0, & \text { if } Q_{r} \geq d_{1}+d_{2} \\ d_{1}+d_{2}-Q_{r}, & \text { if } Q_{r}+q_{0} \geq d_{1}+d_{2}>Q_{r} \\ q_{0}, & \text { if } d_{1}+d_{2}>Q_{r}+q_{0}\end{cases}
$$

where the market demand for both selling periods does not exceed the retailer's wholesale order quantity, i.e., $d_{1}+d_{2} \leq Q_{r}$, the option will not be exercised by the retailer; the retailer will choose to exercise the option when the market demand is between the firm order quantity and the total order quantity, i.e., $Q_{r}+q_{0} \geq d_{1}+d_{2}>Q_{r}$, at which point the option exercised quantity is $q=\min \left(d_{1}+d_{2}-Q_{r}, Q_{s}-Q_{r}\right)=d_{1}+d_{2}-Q_{r}$. When the total order quantity cannot meet the greater market demand, i.e., $d_{1}+d_{2}>Q_{r}+q_{0}$, the retailer will exercise all options, i.e., $q=q_{0}$.

We initially study the retailer's optimal ordering decision-making in this supply chain. As indicated in Section 3, the retailer's profit function $\pi_{r}$ is as follows (Note $(A)^{+}=\max (0, A)$ ):

$$
\Pi_{r}=p_{1} \min \left(d_{1}, Q_{r}+q\right)+p_{2} \min \left(d_{2}, Q_{r}+q-d_{1}\right)-w Q_{r}-w_{1} q_{0}-w_{2} q-h\left(d_{1}+d_{2}-Q_{r}-q_{0}\right)^{+},
$$

where the first item is the sales revenue in the first period, and the second item is the sales revenue in the second period. The third, fourth and fifth items are the cost of directly ordering fresh agricultural products, the cost of ordering options, and the cost of exercising options on demand, respectively. The last item is the cost of shortage.

Theorem 4.1. When the sales price has a two-period change, the optimal wholesale order quantity and optimal option order quantity for the retailer are as follows:

$$
\begin{aligned}
Q_{r}^{*} & =\left[\left(\alpha-\beta_{1} p_{1}\right) \lambda_{1}+\left(\alpha-\beta_{2} p_{2}+\gamma p_{1}\right) \lambda_{2}\right] F^{-1}\left(1-\frac{w-w_{1}}{w_{2}}\right), \\
q_{0}^{*} & =\left(\alpha-\beta_{1} p_{1}\right) \lambda_{1} F^{-1}\left(1-\frac{w_{1}}{p_{1}+h-w_{2}}\right)+\left(\alpha-\beta_{2} p_{2}+\gamma p_{1}\right) \lambda_{2} F^{-1}\left(1-\frac{w_{1}}{p_{2}+h-w_{2}}\right)-Q_{r}^{*} .
\end{aligned}
$$

The optimal total order quantity is

$$
Q_{r}^{*}+q_{0}^{*}=\left(\alpha-\beta_{1} p_{1}\right) \lambda_{1} F^{-1}\left(1-\frac{w_{1}}{p_{1}+h-w_{2}}\right)+\left(\alpha-\beta_{2} p_{2}+\gamma p_{1}\right) \lambda_{2} F^{-1}\left(1-\frac{w_{1}}{p_{2}+h-w_{2}}\right) .
$$

Proof. The retailer's expected profit function is given by equation (4.2).

The first partial derivatives of $Q_{r}$ and $q_{0}$ are calculated as follows:

$$
\begin{aligned}
& \frac{\partial \Pi_{r}}{\partial Q_{r}}=\left(w_{2}-p_{1}-h\right) F\left(\frac{Q_{r}+q_{0}}{\left(\alpha-\beta_{1} p_{1}\right) \lambda_{1}}\right)-w_{2} F\left(\frac{Q_{r}}{\left(\alpha-\beta_{2} p_{2}+\gamma p_{1}\right) \lambda_{2}}\right)+p_{1}+p_{2}+h-w, \\
& \frac{\partial \Pi_{r}}{\partial q_{0}}=\left(w_{2}-p_{1}-h\right) F\left(\frac{Q_{r}+q_{0}}{\left(\alpha-\beta_{1} p_{1}\right) \lambda_{1}}\right)-w_{2}+p_{1}+p_{2}+h-w_{1} .
\end{aligned}
$$

By determining the profit function $\pi_{r}$ of the stagnation point of $L\left(Q_{r}, q_{0}\right)$, we can obtain the Hessian matrix $H(L)$ by using equations (4.6) and (4.7).

$$
H(L)=\left(\begin{array}{ll}
\frac{\left(w_{2}-p_{1}-h\right)}{\left(\alpha-\beta_{1} p_{1}\right) \lambda_{1}} f\left(\varepsilon_{2}\right)-\frac{w_{2}}{\left(\alpha-\beta_{2} p_{2}+\gamma p_{1}\right) \lambda_{2}} f\left(\varepsilon_{1}\right) & \frac{\left(w_{2}-p_{1}-h\right)}{\left(\alpha-\beta_{1} p_{1}\right) \lambda_{1}} f\left(\varepsilon_{2}\right) \\
\frac{\left(w_{2}-p_{1}-h\right)}{\left(\alpha-\beta_{1} p_{1}\right) \lambda_{1}} f\left(\varepsilon_{2}\right) & \frac{\left(w_{2}-p_{1}-h\right)}{\left(\alpha-\beta_{1} p_{1}\right) \lambda_{1}} f\left(\varepsilon_{2}\right)
\end{array}\right),
$$

where $\varepsilon_{1}=\frac{d_{1}}{\left(\alpha-\beta_{1} p_{1}\right) \lambda_{1}}$, and $\varepsilon_{2}=\frac{d_{2}}{\left(\alpha-\beta_{2} p_{2}+\gamma p_{1}\right) \lambda_{2}}$. 
According to the previous assumptions in Section 3, $0<w<w_{1}+w_{2}, 0<w_{1}+w_{2}<p_{1}+h$, and $f(x)>0$. We can know that the first-order principal minor determinant $\left[\frac{\left(w_{2}-p_{1}-h\right)}{\left(\alpha-\beta_{1} p_{1}\right) \lambda_{1}} f\left(\varepsilon_{2}\right)-\frac{w_{2}}{\left(\alpha-\beta_{2} p_{2}+\gamma p_{1}\right) \lambda_{2}} f\left(\varepsilon_{1}\right)\right]<0$, and the second-order principal minor determinant $\left|\begin{array}{lr}\frac{\left(w_{2}-p_{1}-h\right)}{\left(\alpha-\beta_{1} p_{1}\right) \lambda_{1}} f\left(\varepsilon_{2}\right)-\frac{w_{2}}{\left(\alpha-\beta_{2} p_{2}+\gamma p_{1}\right) \lambda_{2}} f\left(\varepsilon_{1}\right) & \frac{\left(w_{2}-p_{1}-h\right)}{\left(\alpha-\beta_{1} p_{1}\right) \lambda_{1}} f\left(\varepsilon_{2}\right) \\ \frac{\left(w_{2}-p_{1}-h\right)}{\left(\alpha-\beta_{1} p_{1}\right) \lambda_{1}} f\left(\varepsilon_{2}\right) & \frac{\left(w_{2}-p_{1}-h\right)}{\left(\alpha-\beta_{1} p_{1}\right) \lambda_{1}} f\left(\varepsilon_{2}\right)\end{array}\right|-$ $\frac{w_{2}}{\left(\alpha-\beta_{2} p_{2}+\gamma p_{1}\right) \lambda_{2}} f\left(\varepsilon_{1}\right) * \frac{\left(w_{2}-p_{1}-h\right)}{\left(\alpha-\beta_{1} p_{1}\right) \lambda_{1}} f\left(\varepsilon_{2}\right)>0$. Therefore, Hesse matrix of the profit function is non-positive definite. Thus, $\pi_{r}$ is a joint concave function about $Q_{r}$ and $q_{0}$, and there is at least one global maximum point. The function gets the maximum at point $\left(Q_{r}^{*}, q_{0}^{*}\right)$.

Let the first derivative $\frac{\partial \Pi_{r}}{\partial Q_{r}}=0, \frac{\partial \Pi_{r}}{\partial q_{0}}=0$ to obtain:

$$
\begin{aligned}
& Q_{r}^{*}=\left[\left(\alpha-\beta_{1} p_{1}\right) \lambda_{1}+\left(\alpha-\beta_{2} p_{2}+\gamma p_{1}\right) \lambda_{2}\right] F^{-1}\left(1-\frac{w-w_{1}}{w_{2}}\right), \\
& q_{0}^{*}=\left(\alpha-\beta_{1} p_{1}\right) \lambda_{1} F^{-1}\left(1-\frac{w_{1}}{p_{1}+h-w_{2}}\right)+\left(\alpha-\beta_{2} p_{2}+\gamma p_{1}\right) \lambda_{2} F^{-1}\left(1-\frac{w_{1}}{p_{2}+h-w_{2}}\right)-Q_{r}^{*} .
\end{aligned}
$$

Theorem 4.2. The optimal total wholesale price quantity $Q_{r}^{*}$ of fresh agricultural products is inversely proportional to the retail price $p_{1}$ when considering the two-period sales price.

If $\beta_{2}>\frac{\lambda_{1}}{\lambda_{2}} \gamma, Q_{r}^{*}$ is inversely proportional to the price $p_{2}$ in the second period.

If $\frac{\lambda_{1}}{\lambda_{2}} \gamma>\beta_{2}>\gamma, Q_{r}^{*}$ is positively proportional to the price $p_{2}$ in the second period.

Proof. Equation (4.3) is converted as follows:

$$
Q_{r}^{*}=\left(\alpha \lambda_{1}+\alpha \lambda_{2}-\lambda_{1} \beta_{1} p_{1}+\lambda_{2} \beta_{2} p_{2}-\lambda_{2} \gamma p_{1}\right) F^{-1}\left(1-\frac{w-w_{1}}{w_{2}}\right) .
$$

The derivative of $p_{1}$ is: $\frac{\partial Q_{r}^{*}}{\partial p_{1}}=-\left(\lambda_{1} \beta_{1}-\gamma \lambda_{2}\right) F^{-1}\left(1-\frac{w-w_{1}}{w_{2}}\right)$. According to the foregoing assumption, $\beta_{1}>$ $\gamma>0$, at this point $\frac{\partial Q_{r}^{*}}{\partial p_{1}}<0, Q_{r}^{*}$ is a decreasing function of $p_{1}$. Similarly, $\frac{\partial Q_{r}^{*}}{\partial p_{2}}=-\left(\lambda_{2} \beta_{2}-\gamma \lambda_{1}\right) F^{-1}\left(1-\frac{w-w_{1}}{w_{2}}\right)$. If $\beta_{2}>\frac{\lambda_{1}}{\lambda_{2}} \gamma, Q_{r}^{*}$ is a decreasing function of $p_{2}$; if $\frac{\lambda_{1}}{\lambda_{2}} \gamma>\beta_{2}>\gamma, Q_{r}^{*}$ is an increasing function of $p_{2}$.

\section{SupplieR's OPTIMAL OUTPUT DECISION-MAKING}

We consider the optimal pricing decision-making of a fresh agricultural products supplier under the condition of allowing shortage. Based on the assumptions and descriptions of the model in Section 3, the supplier produces according to the retailer's order, and the profit function is denoted as $\Pi_{s}$.

$$
\Pi_{s}=w Q_{r}^{*}+w_{1} q_{0}^{*}+w_{2} \min \left(d_{1}+d_{2}-Q_{r}^{*}, q_{0}^{*}\right)-c Q_{s}-g \min \left(Q_{r}^{*}+q_{0}^{*}-Q_{s}\right)^{+},
$$

where the first item is the sales revenue from the retailer's wholesale orders, the second item is the sales revenue from the retailer's option orders, the third item is the revenue when the options are exercised, the fourth item is the supplier's production costs, and the last item is the supplier's shortage penalty.

Theorem 5.1. The optimal output of the supplier based on the option contract meets the following requirements:

$$
Q_{s}^{*}= \begin{cases}Q_{r}^{*}, & \text { if } 0 \leq Q_{s}<Q_{r}^{*} \\ Q_{s}, & \text { if } Q_{r}^{*} \leq Q_{s}<Q_{r}^{*}+q_{0}^{*} \\ Q_{s}^{*}+q_{0}^{*}, & \text { if } Q_{r}^{*}+q_{0}^{*} \leq Q_{s}\end{cases}
$$

where $Q_{s}=\left(\alpha-\beta_{1} p_{1}\right) \lambda_{1} F^{-1}\left(1-\frac{c}{g+w_{2}}\right)+\left(\alpha-\beta_{2} p_{2}+\gamma p_{1}\right) \lambda_{2} F^{-1}\left(1-\frac{c}{g+w_{2}}\right)$. 
Proof. (1) Combined with the assumption: $\frac{\partial \Pi_{s}}{\partial Q_{s}}=s-c>0, \frac{\partial \Pi_{s}}{\partial Q_{s}}=-c<0$, the derivatives of profit function $\Pi_{s}$ of the supplier of fresh agricultural products can be obtained when $Q_{s}<Q_{r}^{*}$ and $Q_{s} \geq Q_{r}^{*}+q_{0}^{*}$. If $Q_{s}<Q_{r}^{*}$, there profit function increases monotonically; if $Q_{s} \geq Q_{r}^{*}+q_{0}^{*}$, the profit function decreases monotonically. Hence, the optimal yield is $Q_{s}^{*}=Q_{r}^{*}+q_{0}^{*}$.

(2) When $Q_{r}^{*} \leq Q_{s}<Q_{r}^{*}+q_{0}^{*}$, the supplier's production output is between the wholesale price order quantity and the total order quantity.

The first and second derivatives of $\Pi_{s}$ in equation (5.1) are obtained as follows:

$$
\begin{aligned}
\frac{\partial \Pi_{s}}{\partial Q_{s}} & =\left(w_{2}+g-c\right)-\left(w_{2}+g\right)\left(F^{-1}\left(\frac{Q_{s}}{\left(\alpha-\beta_{1} p_{1}\right) \lambda_{1}}\right)+F^{-1}\left(\frac{Q_{s}}{\left(\alpha-\beta_{2} p_{2}+\gamma p_{2}\right) \lambda_{2}}\right)\right), \\
\frac{\partial^{2} \Pi_{s}}{\partial Q_{s}} & =-\frac{\left(w_{2}+g\right)}{\left(\alpha-\beta_{1} p_{1}\right) \lambda_{1}} f\left(\frac{Q_{s}}{\left(\alpha-\beta_{1} p_{1}\right) \lambda_{1}}\right)-\frac{\left(w_{2}+g\right)}{\left(\alpha-\beta_{2} p_{2}+\gamma p_{2}\right) \lambda_{2}} f\left(\frac{Q_{s}}{\left(\alpha-\beta_{2} p_{2}+\gamma p_{2}\right) \lambda_{2}}\right)<0 .
\end{aligned}
$$

Set the first derivative be equal to zero. Then the optimal output is given by the expression:

$$
Q_{s}^{*}=\left(\alpha-\beta_{1} p_{1}\right) \lambda_{1} F^{-1}\left(1-\frac{c}{g+w_{2}}\right)+\left(\alpha-\beta_{2} p_{2}+\gamma p_{1}\right) \lambda_{2} F^{-1}\left(1-\frac{c}{g+w_{2}}\right) .
$$

In order to ensure that there are enough fresh agricultural products to meet the retailer's demand, i.e., $Q_{s}^{*} \geq Q_{r}^{*}+q_{0}^{*}$, according to equations (4.5) and (5.5), the following conditions must be met:

$$
\begin{aligned}
& \left(a-\beta_{1} p_{1}\right) \lambda_{1} F^{-1}\left(1-\frac{c}{g+w_{2}}\right)+\left(\alpha-\beta_{2} p_{2}+\gamma p_{1}\right) \lambda_{2} F^{-1}\left(1-\frac{c}{g+w_{2}}\right) \\
& \quad>\left(a-\beta_{1} p_{1}\right) \lambda_{1} F^{-1}\left(1-\frac{w_{1}}{p_{1}+h-w_{2}}\right)+\left(\alpha-\beta_{2} p_{2}+\gamma p_{1}\right) \lambda_{2} F^{-1}\left(1-\frac{w_{1}}{p_{2}+h-w_{2}}\right) .
\end{aligned}
$$

Thus, $g>\frac{c}{w_{1}}\left(p_{2}+h-w_{2}\right)-w_{2}$, when the supplier's shortage penalty cost $g$ is large enough, the supplier's optimal production output $Q_{s}^{*}$ will exceed the retailer's total order quantity $Q_{r}^{*}+q_{0}^{*}$. When the default risk is reduced, a production output equal to the order quantity will be the supplier's optimal decision-making.

\section{Coordination in the fresh agricultural Produce Supply Chain}

According to the aforementioned assumptions, the conditions for supply chain coordination are

$$
\begin{aligned}
\frac{w_{1}}{p_{1}+h-w_{2}} & =\frac{c}{p_{1}+h}, \\
\text { and } \frac{w_{1}}{p_{2}+h-w_{2}} & =\frac{c}{p_{2}+h} .
\end{aligned}
$$

Under the scenario of two-period prices, equations (6.1) and (6.2) will not coincide with two-price formula simultaneously because $p_{1}>p_{2}$. The result implies a failure to coordinate the supply chain, indicating that a coordinated supply chain in the first period will not be coordinated in the other period.

For achieving coordination with the first period price $p_{1}$ and the second period price $p_{2}$, the supply chain is introduced into a cost-sharing contract which means that the retailer bears a proportional share of the cost $\phi$, while the supplier bears the cost of $1-\phi, 0<\phi<1$.

With the introduction of cost-sharing contract, the profit function of the retailer is:

$$
\begin{aligned}
\pi_{r}= & p_{1} \min \left(d_{1}, Q_{r}+q_{0}-d_{2}\right)+p_{2} \min \left(d_{2}, Q_{r}+q_{0}-d_{1}\right)-h\left(d_{1}+d_{2}-Q_{r}-q_{0}\right)^{+} \\
& -w_{2} \min \left(q_{0},\left(d_{1}+d_{2}-Q_{r}\right)^{+}\right)-(w+\emptyset c) d_{1}-\left(w_{1}+\emptyset c\right) q_{0} .
\end{aligned}
$$


Then, we get the first and second derivatives as follows:

$$
\begin{aligned}
& \frac{\partial \Pi_{r}}{\partial Q_{r}}=\left(w_{2}-p_{1}-h\right) F\left(\frac{Q_{r}+q_{0}}{\left(\alpha-\beta_{1}\right) \lambda_{1}}\right)-w_{2} F\left(\frac{Q_{r}}{\left(\alpha-\beta_{2} p_{2}+\gamma p_{1}\right) \lambda_{2}}\right)+p_{1}+p_{2}+h-w-\phi c, \\
& \frac{\partial \Pi_{r}}{\partial q_{0}}=\left(w_{2}-p_{1}-h\right) F\left(\frac{Q_{r}+q_{0}}{\left(\alpha-\beta_{1} p_{1}\right) \lambda_{1}}\right)-w_{2}+p_{1}+p_{2}+h-w_{1}-\phi c .
\end{aligned}
$$

We can obtain the retailer's optimal wholesale price order quantity and optimal option order quantity respectively as follows:

$$
\begin{aligned}
Q_{r}^{*} & =\left[\left(\alpha-\beta_{1} p_{1}\right) \lambda_{1}+\left(\alpha-\beta_{2} p_{2}+\gamma p_{1}\right) \lambda_{2}\right] F^{-1}\left(1-\frac{w-w_{1}+\phi c}{w_{2}}\right), \\
q_{0}^{*} & =\left(\alpha-\beta_{1} p_{1}\right) \lambda_{1} F^{-1}\left(1-\frac{w_{1}+\emptyset c}{p_{1}+h-w_{2}}\right)+\left(\alpha-\beta_{2} p_{2}+\gamma p_{1}\right) \lambda_{2} F^{-1}\left(1-\frac{w_{1}+\emptyset c}{p_{2}+h-w_{2}}\right)-Q_{r}^{*} .
\end{aligned}
$$

With the introduction of cost-sharing contract, the supplier's profit function is:

$$
\Pi_{s}=(w-c+\phi c) Q_{r}+\left(w_{1}-c+\phi c\right) q_{0}+w_{2} \min \left(q_{0},\left(d_{1}+d_{2}-Q_{r}\right)^{+}\right) .
$$

The following expression $\phi$ can be obtained:

$$
\begin{gathered}
1-\frac{c}{p_{2}+h}=1-\frac{w_{1}+\phi c}{p_{2}+h-w_{2}}, \text { namely } \phi=1-\frac{w_{2}}{p_{2}+h}-\frac{w_{1}}{c}, \\
\text { or } 1-\frac{c}{p_{1}+h}=1-\frac{w_{1}+\phi c}{p_{1}+h-w_{2}}, \text { namely } \phi=1-\frac{w_{2}}{p_{1}+h}-\frac{w_{1}}{c} .
\end{gathered}
$$

The supply chain will be coordinated when a two-period pricing strategy is considered in the first period at $\frac{w_{1}}{p_{1}+h-w_{2}}=\frac{c}{p_{1}+h}$, or in the second period at $\frac{w_{1}}{p_{2}+h-w_{2}}=\frac{c}{p_{2}+h}$. The sharing ratio $\phi$ of the cost-sharing contract in the two periods needs to meet equations (6.9) and (6.10) to ensure that the coordinated order quantity increases, the supply chain is stable, and achieve win-win and overall optimization.

\section{Numerical ANALYSis}

Assume that a supermarket retailer $F$ has a transaction with a local agricultural cooperative for a fresh produce $L$. Both parties deal under a wholesale order and option order pattern. During the production season of product $L$, after the two parties sign the wholesale and option contract, the retailer pays the order amount and option fee, and agrees on the wholesale price and order quantity that the both parties will deal with during the selling season. At the same time, if the option exercise price is lower than the actual market price during the selling season with strong market demand, the retailer will exercise the option accordingly and supplement the purchase of product $L$ at a lower option exercise price to further increase its profit. In the contract, it is agreed that the wholesale price is $w=8(\mathrm{CNY} / \mathrm{kg})$, the production cost is $c=7(\mathrm{CNY} / \mathrm{kg})$, the shortage cost is $h=2(\mathrm{CNY} / \mathrm{kg})$, and the random factor of market demand is $\varepsilon \in U[0,1]$. According to the practical situation, we set the parameters as: $a=3000, b_{1}=20, b_{2}=11, \gamma=4, \lambda_{1}=0.84, \lambda_{2}=0.5, w_{1}=3, w_{2}=9$.

\subsection{Relationship between optimal order quantity and option exercise price}

In the retailer's revenue model for a single period, the retailer will choose the strategy $\left(Q_{d}^{*}, q_{0}^{*}\right)$, where $Q_{d}^{*}=(a-\beta p) \lambda F^{-1}\left(1-\frac{w-w_{1}}{w_{2}}\right)$, and $q_{0}^{*}=(a-\beta p) \lambda F^{-1}\left(1-\frac{w_{1}}{p+h-w_{2}}\right)-Q_{d}^{*}$. Table 2 shows how for a given option price $q_{0}$, the optimal order quantity (in $\mathrm{kg}$ ) of the change in option exercise price was calculated by Matlab.

Figure 2 shows the fluctuation relationship between the optimal order quantity and the option exercise price based on the above data. 
TABLE 2. Relationship between the optimal order quantity and option exercise price.

\begin{tabular}{llllllllll}
\hline \hline Option exercise price & 5.00 & 5.50 & 6.00 & 6.50 & 7.00 & 7.50 & 8.00 & 8.50 & 9.00 \\
\hline Wholesale order quantity & 0.00 & 266.55 & 486.40 & 694.45 & 860.20 & 974.00 & 1094.40 & 1199.88 & 1296.62 \\
Option order quantity & 2249.10 & 1926.60 & 1655.36 & 1414.22 & 1186.65 & 975.10 & 765.02 & 552.05 & 330.80 \\
Total order quantity & 2249.10 & 2193.15 & 2141.76 & 2108.67 & 2046.85 & 1949.10 & 1859.42 & 1751.93 & 1627.42 \\
\hline
\end{tabular}

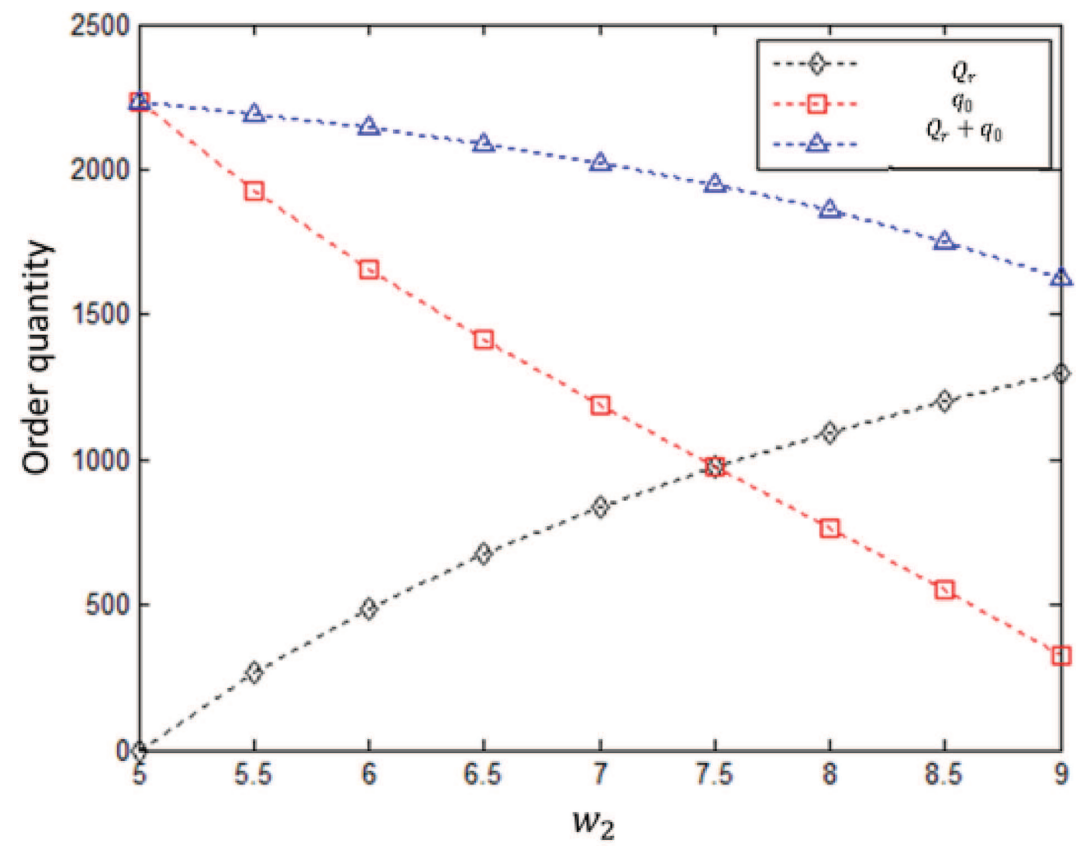

FIGURE 2. Relationship between the optimal order quantity and option exercise price.

Figure 2 shows the influence of the option exercise price on the optimal order quantity, and thus on the retailer's optimal ordering decision-making. By increasing the option exercise price $w_{2}$, the retailer's demand for option orders decreases, thereby increasing the fixed order quantity to compensate for the market demand. When there is an excessive rise in option exercise price, there will be a decline in both exercise probability of the option and its intrinsic value. As a result, the option order will be replaced by a fixed order quantity. In this scenario, the proportion of fixed orders in total orders is higher, while the proportion of option orders in total orders is correspondingly low, thus reducing market demand and risk.

Lemma 7.1. In order to maximize the portfolio contract and avoid the risk of price fluctuation, both parties should consider each other's interests and agree on a reasonable wholesale price and an option exercise price.

\subsection{Relationship between total supply chain profit and two-period prices}

The total profit of the supply chain partners was calculated by Matlab. Figure 3 shows the relationship between the retailer's total profit and the pricing in two periods. Figure 4 shows the relationship between the supplier's total profit and the pricing in two periods.

Figure 3 describes the distribution of the retailer's total profit under price changes. Obviously, the retailer's total profit increases with the rise of the two-period price. The rise in total profit with $p_{2}$ was slow compared 


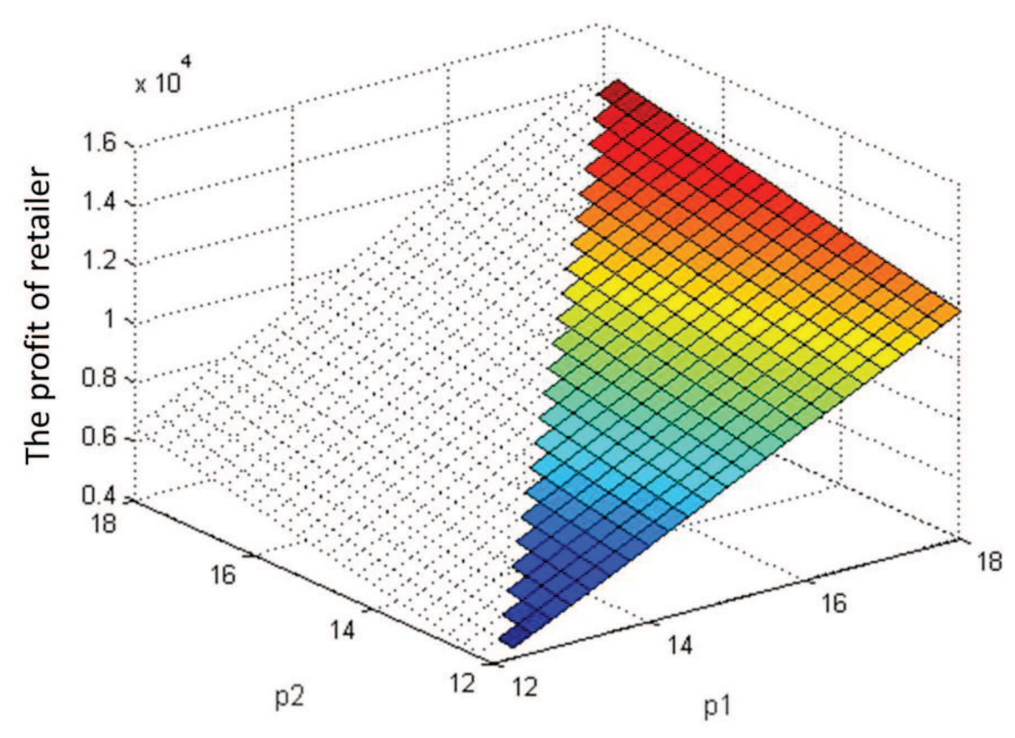

Figure 3. Relationship between the retailer's total profit and $p_{1}, p_{2}$.

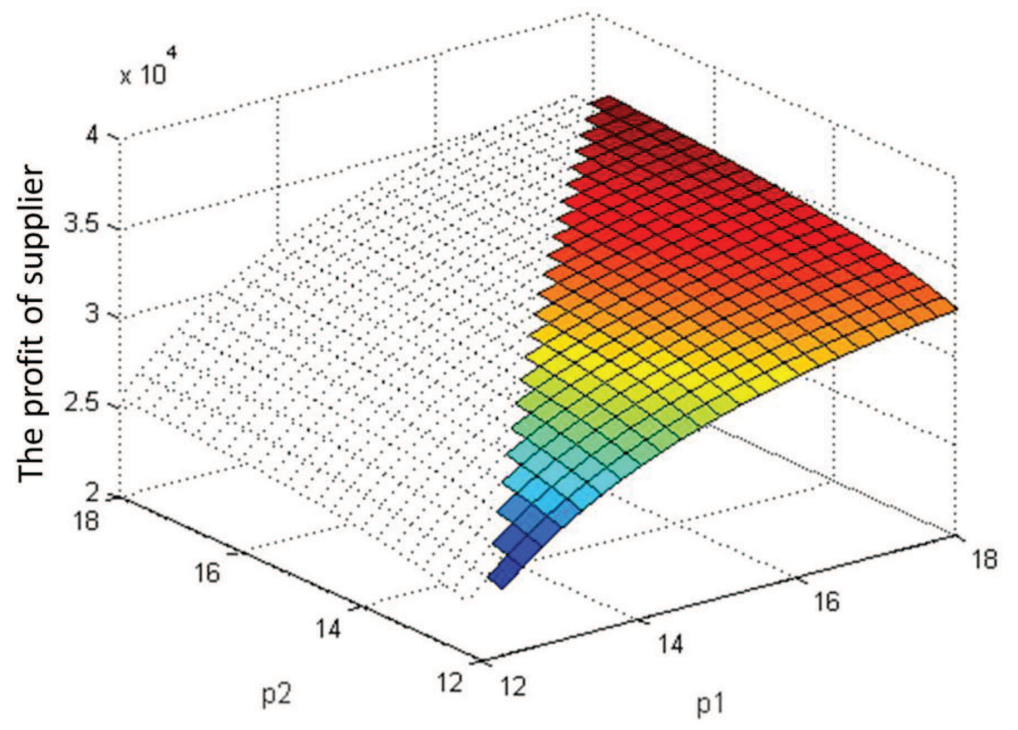

FiguRE 4. Relationship between the supplier's total profit and $p_{1}, p_{2}$.

to the rapid increase in total profit with $p_{1}$, because the first-period market demand increases significantly with the launch of the product, resulting in a significant increase in profits. Meanwhile, the price elasticity in the second period decreases gradually with the decline of demand. Therefore, the total profit increased slowly with the increase of $p_{2}$.

As shown in Figure 4, the supplier's total profit increases rapidly with $p_{1}$ and gradually with $p_{2}$. For the two-period selling of fresh agricultural produce, the supplier's output is determined by the retailer's order. For the supplier, a higher selling price $p_{2}$ in the second period of reduced sales means a higher profit per product unit 


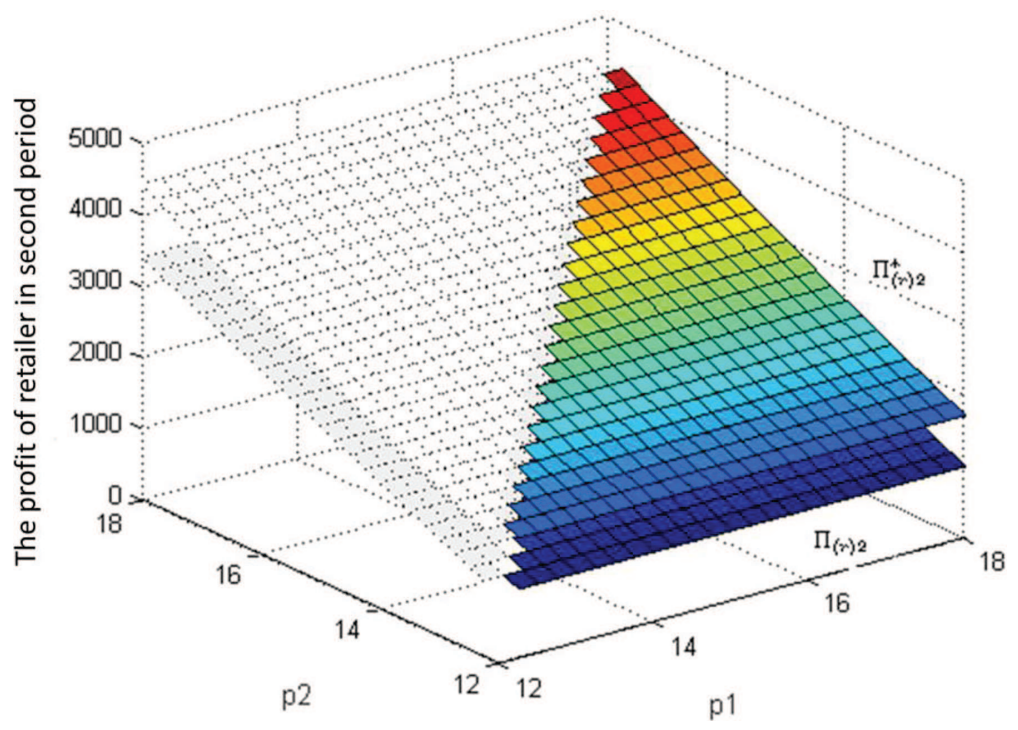

FiguRE 5. Second-period profit of the retailer with or without a cost-sharing contract.

because the production cost per product unit is basically fixed. When the market demand grows, the supplier's profit increases with the increase of the retailer's order quantity.

Lemma 7.2. In the second period, due to the fixed cost of the supplier, the supplier's profit will decrease along with the decline of sales revenue.

\subsection{Two-period supply chain coordination for fresh agricultural produce}

A cost-sharing contract is introduced, in which the cost is shared by both supply chain members. Through Matlab calculations, the relationship between profit and price change is obtained, as shown in Figures 5 and 6 .

In Figures 5 and $6, \Pi_{r}$ and $\Pi_{s}$ represent the profits of the retailer and supplier without a cost-sharing contract under the decentralized decision-making, respectively; $\Pi_{r}^{*}$ and $\Pi_{s}^{*}$ represent the profit of the retailer and supplier with a cost-sharing contract under the decentralized decision-making, respectively. As shown in the figures, $\Pi_{r}^{*}>\Pi_{r}, \Pi_{s}^{*}>\Pi_{s}$. The findings indicate that the cost-sharing contract effectively brings greater profits to the supply chain members compared with the supply chain members without a cost-sharing contract.

Lemma 7.3. The cost-sharing contract enables the supply chain to coordinate under a two-period pricing strategy, increase the profits of supply chain members and achieving a win-win situation.

It is found that when the retailer adopts two-period pricing in selling fresh agricultural products, the reduction of the first-period price will increase the quantity of orders at the optimal wholesale price, but the reduction of the second-period price will not increase the quantity of orders at the optimal wholesale price. An optimal two-period price combination maximized the optimal option order quantity and the optimal total order quantity. At the beginning of price reduction, the influence of price change on the profits of both the supplier and the retailer is not very obvious. However, with the decline of price, the supplier's profit also decreases. To stabilize the supply chain, the retailer introduced a cost-sharing contract based on the option contract, which realizes the coordination of the supply chain again. Therefore, when the retailer adopts a two-period pricing strategy, it is necessary to establish a reasonable price and cost-sharing ratio coefficient to create a mutually beneficial situation for all members of the supply chain. 


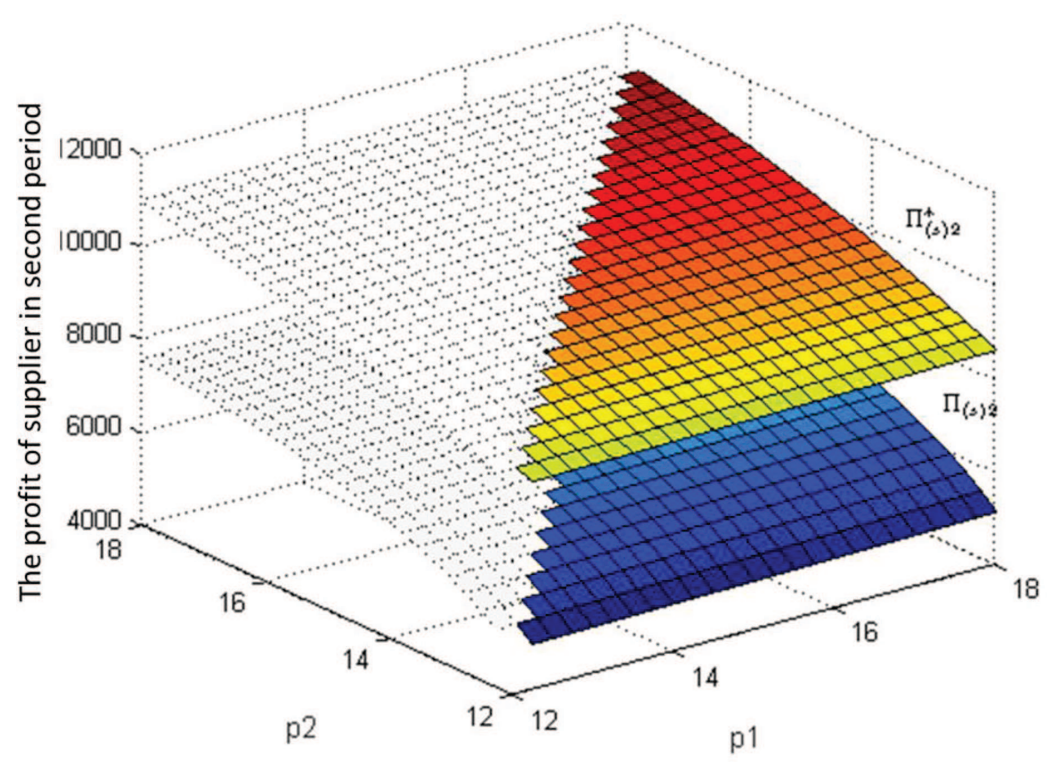

FIGURE 6. Second-period profit of the supplier with or without a cost-sharing contract.

\section{Conclusions}

Fresh agricultural produce is naturally perishable and is almost the staple food and necessity of people's daily diet all over the world. Its market demand changes with the change of freshness and price. Because of the change of freshness, the retailer has to adopt a multi-period pricing strategy to deal with unsold products. The imbalance between supply and demand caused by the fragmentation and information asymmetry in the fresh produce market is particularly serious in the fresh agricultural produce supply chain, while the freshness of fresh produce also determines a high uncertainty of market demand. Option contract has become increasingly popular in recent years under the decentralized situation and information asymmetry in supply chain management. This study explores the optimal decision-making of option contracts under two-period price and the coordination conditions in the fresh agricultural produce supply chain.

Through a dynamic pricing strategy, the following results discuss how two-period pricing affects the optimal ordering, profitability, and coordination of supply chain members.

(1) The quantity of orders at the optimal wholesale price increases with the decline of the price in the first period, and then becomes more stable with the decline of the price in the second period. In contrast, the price change in the first period is considered to have a greater impact on the optimal order quantity decisionmaking. Both the optimal option order quantity and the optimal total order quantity are concave functions of two-period prices. The existence of an optimal price maximizes the optimal option order quantity and the optimal total order quantity.

(2) In this case, with the rise of price in the first period, the profits of supply chain members (the retailer and the supplier) increase significantly, while the impact of price change in the second period on profits is not obvious. Although the impact of price change in the second period on profits is not obvious, it is still necessary to consider two-period price sales because with the decrease of the freshness of the product, the sales cannot be guaranteed if the same price is maintained, thus affecting the whole fresh produce supply chain.

(3) The original option contract can only coordinate the supply chain at the first-period price under a decentralized decision-making. Therefore, the introduction of the cost-sharing contract in the second period increases 
the retailer's orders, coordinates the supply chain, and also increases profits for both the supplier and the retailer. This finding is of great significance to the multi-period pricing of fresh agricultural products ordered by the retailer through the option contract.

Therefore, the option contract plays a significant positive role in the risk management of fresh agricultural produce supply chain. The results of this study have valuable implications for practical decision-making in real-world supply chains.

It is worth considering four issues for future research directions. Firstly, this model only considers two supply chain partners: the retailer and supplier. In fact, the fresh agricultural produce supply chain in the real world is always composed of multiple members and participants, who may compete with each another. Therefore, an important research direction to consider will be to study more complex market structure [3,5]. Secondly, different consumers have different preferences for freshness, but they do not investigate the impact of consumer behavior on the supply chain management. In the future, we can consider classifying consumers and studying specific market segments according to consumer behavior. Thirdly, this study only considers the profitability of two-period pricing. Future analysis can be extended to multi-period pricing. Finally, this research area will benefit from the investigation of new modern scenarios such as combined online and offline retail.

Acknowledgements. This work was supported by National Natural Science Foundation of China (71871098), Humanities and Social Sciences Foundation of Ministry of Education of China (18YJA630127), and Soft Science Research Project of Guangdong Province, China (2019A101002119).

\section{REFERENCES}

[1] S. Bhattacharjee and R. Ramesh, A multi-period profit maximizing model for retail supply chain management: An inegration of demand and supply-side mechanisms. Eur. J. Oper. Res. 122 (2000) 584-601.

[2] G. Cachon and R. Swinney, Purchasing, pricing, and quick response in the presence of strategic consumers. Manage. Sci. 55 (2009) 497-511.

[3] A. Cheaitou and R. Cheaytou, A two-stage capacity reservation supply contract with risky supplier and forecast updating. Int. J. Prod. Econ. 209 (2019) 42-60.

[4] X. Chen, G. Hao and L. Lee, Channel coordination with a loss-averse retailer and option contracts. Int. J. Prod. Econ. 150 (2014) 52-57.

[5] X. Chen, P. Hu, S. Shum and Y.H. Zhang, Dynamic stochastic inventory management with reference price effects. Oper. Res. 64 (2016) 1529-1536.

[6] X. Chen, B. Lee and S.M. An, Option contract design for supply chains under asymmetric cost information. Kybernetes 48 (2019) 835-860.

[7] E.P. Chew, C. Lee, R. Liu, K.S. Hong and A. Zhang, Optimal dynamic pricing and ordering decisions for perishable products. Int. J. Prod. Econ. 157 (2014) 39-48.

[8] S. Dasu and C. Tong, Dynamic pricing when consumers are strategic: analysis of posted and contingent pricing schemes, Eur. J. Oper. Res. 204 (2010) 662-671.

[9] K. Eriksson, An option mechanism to coordinate a dyadic supply chain bilaterally in a multi-period setting. Omega-Int. J. Manage. Sci. 88 (2019) 133-149.

[10] Y. Feng and Q. Wu, Option contract design and risk analysis: supplier's perspective. Asia-Pac. J. Oper. Res. 35 (2018) 1850017.

[11] Q. Fu, S.X. Zhou, X. Chao and C.Y. Lee, Combined pricing and portfolio option procurement. Prod. Oper. Manage. 21 (2012) $361-377$.

[12] K. Inderfurth, P. Kelle and R. Kleber, Dual sourcing using capacity reservation and spot market: optimal procurement policy and heuristic parameter determination. Eur. J. Oper. Res. 225 (2013) 298-309.

[13] K. Jörnsten, S.L. Nonås, L. Sandal and J. Ubøe, Transfer of risk in the newsvendor model with discrete demand. Omega-Int. J.Manage. Sci. 40 (2012) 404-414.

[14] J. Li, X. Liu, J. Wu and F. Yang, Coordination of supply chain with a dominant retailer under demand disruptions. Math. Prob. Eng. 2014 (2014) 854681.

[15] J.C. Li, Y.W. Zhou and W. Huang, Production and procurement strategies for seasonal product supply chain under yield uncertainty with commitment-option contracts. Int. J. Prod. Econ. 183 (2016) 208-222.

[16] Z.B. Liu, R. Gao, C. Zhou and N.N. Ma, Two-period pricing and strategy choice for a supply chain with dual uncertain information under different profit risk levels. Comput. Ind. Eng. 136 (2019) 173-186.

[17] J. Luo and X. Chen, Risk hedging via option contracts in a random yield supply chain. Ann. Oper. Res. 257 (2017) 697-719. 
[18] J.R. Luo, X.L. Zhang and X.L. Jiang, Multisources risk management in a supply chain under option contracts. Math. Prob. Eng. 2019 (2019) 7482584.

[19] Z. Luo, X. Chen, J. Chen and X. Wang, Optimal pricing policies for differentiated brands under different supply chain power structures. Eur. J. Oper. Res. 259 (2017) 437-451.

[20] X.L. Ma, S.Y. Wang, S.M.N. Islam and X.B. Liu, Coordinating a three-echelon fresh agricultural products supply chain considering freshness-keeping effort with asymmetric information. Appl. Math. Model. 67 (2019) 337-356.

[21] T. Maiti and B. Giri, Two-period pricing and decision strategies in a two-echelon supply chain under price-dependent demand. Appl. Math. Model. 42 (2017) 655-674.

[22] H. Michelson, S. Boucher, X.Z. Cheng, J.K. Huang and X.P. Jia, Connecting supermarkets and farms: the role of intermediaries in Walmart China's fresh produce supply chains. Renew. Agric. Food Syst. 33 (2018) 47-59.

[23] M. Noori-Daryan, A.A. Taleizadeh and K. Govindan, Joint replenishment and pricing decisions with different freight modes considerations for a supply chain under a composite incentive contract. J. Oper. Res. Soc. (2017). DOI: $10.1057 / \mathrm{s} 41274-017-0270-z$.

[24] I. Nosoohi and A.S. Nookabadi, Designing a supply contract to coordinate supplier's production considering customer-oriented production. Comput. Ind. Eng. 74 (2014) 26-36.

[25] B. Pal, S.S. Sana and K. Chaudhuri, Two-Echelon competitive integrated supply chain model with price and credit period dependent demand. Int. J. Syst. Sci. 47 (2016) 995-100.

[26] K. Pan, K.K. Lai, S. Liang and S.C.H. Leung, Two-period pricing and ordering policy for the dominant retailer in a two-echelon supply chain with demand uncertainty. Omega 37 (2009) 919-929.

[27] S. PiraMuthu and W. Zhou, RFID and perishable inventory management with shelf space and freshness dependent demand. Int. J. Prod. Econ. 144 (2013) 635-640.

[28] I. Popescu and Y.Z. Wu, Dynamic pricing strategies with reference effects. Oper. Res. 55 (2007) $413-429$.

[29] C. Qu, M. He and J. Wang, Strategy for income distribution in Supermarket-Cooperative-Farmer cooperative game under uncertain demand. In: Proceedings of the Fifth international Forum on Decision Science (2018) 225-239.

[30] M. Rahdar and A.S. Nookabadi, Coordination mechanism for a deteriorating item in a two-level supply chain system. Appl. Math. Model. 38 (2014) 2884-2900.

[31] J. Raju and Z.J. Zhang, Channel coordination in the presence of a dominant retailer. Marketing Sci. 24 (2005) $254-262$.

[32] K. Sato and K. Sawaki, A continuous-time dynamic pricing model knowing the competitor's pricing strategy. Eur. J. Oper. Res. 229 (2013) 223-229.

[33] A.A. Taleizadeh and M. Noori-Daryan, Pricing, manufacturing and inventory policies for raw material in a three-level supply chain. Int. J. Syst. Sci. 47 (2016) 919-931.

[34] A.A. Taleizadeh, M. Noori-Daryan and R. Tavakkoli-Moghaddam, Pricing and ordering decisions in a supply chain with imperfect quality items and inspection under buyback of defective items. Int. J. Prod. Res. 53 (2015) 4553-4582.

[35] A.A. Taleizadeh, M. Noori-Daryan and K. Govindan, Pricing and ordering decisions of two competing supply chains with different composite policies: a Stackelberg game-theoretic approach. Int. J. Prod. Res. 54 (2016) 2807-2836.

[36] A.A. Taleizadeh, V.R. Soleymanfar and T.M. Choi, Optimal pricing and alliance strategy in a retailer-led supply chain with the return policy: a game-theoretic analysis. Inf. Sci. 420 (2017) 466-489.

[37] N.N. Wan and X.Z. Wu, Option ordering and coordination strategies for a two-period supply chain. Kybernetes 48 (2019) 471-495.

[38] C. Wang and X. Chen, Option contracts in fresh produce supply chain with circulation loss. J. Ind. Eng. Manage. 6 (2013) $104-112$.

[39] C. Wang and X. Chen, Joint order and pricing decisions for fresh produce with put option contracts. J. Oper. Res. Soc. 69 (2018) 474-484.

[40] R. Wang, S.J. Song and C. Wu, Coordination of supply chain with one supplier and two competing risk-averse retailers under an option contract. Math. Prob. Eng. 2016 (2016) 1970615.

[41] C. Wang, J. Chen, L.L. Wang and J.R. Luo, Supply chain coordination with put option contracts and customer returns. J. Oper. Res. Soc. 71 (2020) 1003-1019.

[42] X.S. Xu and F.T. Chan, Optimal option purchasing decisions for the risk-averse retailer with shortage cost. Asia-Pac. J. Oper. Res. 36 (2019) 1940005.

[43] B. Yan, T. Wang and Y.P. Liu, Decision analysis of retailer-dominated dual-channel supply chain considering cost misreporting. Int. J. Prod. Econ. 178 (2016) 34-41.

[44] X.Y. Yuan, G.B. Bi, B.F. Zhang and Y.G. Yu, Option contract strategies with risk-aversion and emergency purchase. Int. Trans. Oper. Res. 27 (2020) 3079-3103.

[45] H. Zhao, S.J. Song, Y.L. Zhang, J.N.D. Gupta and A.G. Devlin, Optimal decisions of a supply chain with a risk-averse retailer and portfolio contracts. IEEE Access 7 (2019) 123877-123892.

[46] H. Zhao, S.J. Song, Y.L. Zhang, J.N.D. Gupta, A.G. Devlin and R. Chiong, Supply chain coordination with a risk-averse retailer and a combined buy-back and revenue sharing contract. Asia-Pac. J. Oper. Res. 36 (2019) 1950028. 
[47] L.N. Zhou, G.G. Zhou, F.Z. Qi and H.Y. Lee, Research on coordination mechanism for fresh agri-food supply chain with option contracts. Kybernetes $\mathbf{4 8}$ (2019) 1134-1156.

[48] W.Y. Zhuo, L.S. Shao and H.L. Yang, Mean-variance analysis of option contracts in a two-echelon supply chain. Eur. J. Oper. Res. 271 (2018) 535-547.

\section{Subscribe to Open (S20) A fair and sustainable open access model}

This journal is currently published in open access under a Subscribe-to-Open model (S2O). S2O is a transformative model that aims to move subscription journals to open access. Open access is the free, immediate, online availability of research articles combined with the rights to use these articles fully in the digital environment. We are thankful to our subscribers and sponsors for making it possible to publish this journal in open access, free of charge for authors.

\section{Please help to maintain this journal in open access!}

Check that your library subscribes to the journal, or make a personal donation to the S2O programme, by contacting subscribers@edpsciences.org

More information, including a list of sponsors and a financial transparency report, available at: https://www. edpsciences.org/en/maths-s2o-programme 